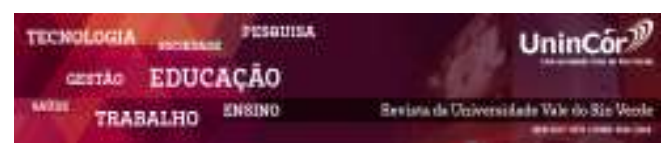

Revista da Universidade Vale do Rio Verde ISSN: 1517-0276 / EISSN: 2236-5362 Vol. 16 | n. 1 | Ano 2018 Universidade do Estado de Mato Grosso charlescaioni1@gmail.com

Edgley Pereira Silva Universidade do Estado de Mato Grosso edyps2004@hotmail.com

Delmonte Roboredo

Universidade do Estado de Mato Grosso roboredo@gmail.com

Gessica de Jesus Oliveira Silva Universidade do Estado de Mato Grosso gessica.unemat@gmail.com

Sheila Caioni

Universidade do Estado de Mato Grosso sheila_caioni@hotmail.com

\section{PROPOSTA DE PAGAMENTO POR SERVIÇOS AMBIENTAIS NA \\ MICROBACIA MARIANA NO \\ MUNICÍPIO DE ALTA FLORESTA, MATO GROSSO}

\section{RESUMO}

O aumento do uso da terra tem ocasionado fortes impactos aos recursos hídricos. No município de Alta Floresta/MT está localizada a microbacia Mariana (MBM) que atua como principal fonte de abastecimento hídrico da população urbana do município. Na perspectiva de identificar ferramentas que permitam a conservação dos recursos hídrico nessa unidade hidrográfica, objetivou-se: (a) identificar quais as principais dificuldades encontradas pelos produtores rurais na tomada de medidas de conservação das Áreas de Preservação Permanente (APP's); (b) elaborar uma proposta de Pagamento por Serviços Ambientais na microbacia hidrográfica Mariana, na perspectiva de contribuir com subsídios para a criação de alternativas de recuperação das APP's degradadas. O presente estudo foi desenvolvido junto aos 95 produtores rurais pertencentes à microbacia. Para atender os objetivos propostos realizaram-se reuniões e visitas as propriedades rurais. Realizou-se ainda um levantamento das principais características da área estudada (uso da terra, número de nascentes e APP's preservadas e degradas, total de unidade consumidoras de água no perímetro urbano). A proposta de pagamento por serviços ambientais foi desenvolvida a partir da análise dos dados levantados. Constatou-se que embora a microbacia apresente um alto potencial hídrico, suas APP's se encontram em elevado estado de degradação. Identificou-se ainda que embora os produtores rurais compreendam a importância da recuperação dessas áreas, a falta de recursos financeiros e de acompanhamento técnico tem se revelado um obstáculo de difícil superação. O programa de Pagamentos por Serviços Ambientais demostrou ser um mecanismo viável e alternativo para a solução dos problemas encontrados na recuperação das APP's.

Palavras-chave: Conservação dos Recursos hídricos. Mata ciliar. Produtor rural. Sustentabilidade.

PROPOSAL FOR PAYMENT FOR ENVIRONMENTAL SERVICES IN MARIANA MICROBACIA IN THE MUNICIPALITY OF ALTA FLORESTA, MATO GROSSO 
unit, the objective was: (a) to identify the main difficulties encountered by rural producers in taking conservation measures for Permanent Preservation Areas (PPA's); (b) to prepare a proposal for Payment for Environmental Services in the Mariana watershed, in order to contribute with subsidies for the creation of alternatives for the recovery of degraded PPAs. The present study was developed with the 95 rural producers belonging to the microbasin. To meet the proposed objectives, meetings and visits to rural properties were held. A survey of the main characteristics of the studied area (land use, number of springs and PPA's preserved and degraded, total of water consuming unit in the urban perimeter) was also carried out. The proposal for payment for environmental services was developed based on the analysis of the data collected. It was verified that although the microbasin presents a high hydric potential, its PPA's are in high state of degradation. It was also identified that although rural producers understand the importance of the recovery of these areas, the lack of financial resources and technical monitoring has proved an obstacle that is difficult to overcome. The Payments for Environmental Services program has proved to be a viable and alternative mechanism for solving the problems encountered in the recovery of PPA's.

Keywords: Conservation of water resources. Ciliary forest. Rural production. Sustainability.

Recebido em: 08/01/2017 - Aprovado em: 10/03/2018 - Disponibilizado em: 15/07/2018

\section{INTRODUÇÃO}

$\mathrm{Na}$ atualidade o uso inadequado da terra em áreas com presença de hidrografias tornou-se tema de debate junto à sociedade, em decorrência de suas implicações a disponibilidade hídrica às gerações futuras. $\mathrm{O}$ homem desde sua origem utilizou-se da terra como meio de sobrevivência; no entanto as diferentes atividades antrópicas têm ocasionado fortes pressões sobre as bacias hidrográficas (LACORTE e ALMEIDA, 2015). Segundo Becker (2001), a ocupação da Amazônia foi percebida como solução para as tensões sociais internas, como a modernização da agricultura no Nordeste e Sudeste, e questões geopolíticas a nível continental e Internacional. Dubreuil et al., (2009) corroboram ao afirmar que a política de ocupação do território de Alta Floresta/MT na década de 70 e 80 , era baseada em um sistema que implicava na exploração total da terra, onde a retirada da mata ao longo dos rios era considerada sinônimo de progresso.

Em meio a este contexto encontra-se a microbacia hidrográfica Mariana (MBM), a qual atua como fonte de abastecimento hídrico das populações urbana e rural. $\mathrm{O}$ ambiente que congrega a microbacia é ecologicamente frágil, o que leva a necessidade da tomada de ações que proporcione a conservação e recuperação das Áreas de Preservação Permanente (APP's) (ZOBY e OLIVEIRA, 2005). Entretanto é preciso salientar que não se deve simplesmente punir os agricultores por não estarem aplicando medidas preventivas, de recuperação e proteção dessas áreas, mas sim entender o porquê de tais 
medidas não estarem sendo tomadas. Altieri (1989) afirma que é necessário conhecer os agroecossistemas e o sistema social produtivo para que se possa compreendê-los e relacioná-los na busca de alternativas para solução dos problemas existentes no meio rural. Pois a busca de uma produção sustentável só ocorrerá com ações de uma organização social que proteja a integridade dos recursos naturais e que assegurem a interação harmônica dos seres humanos, os agroecossistemas e o meio ambiente dentro da perspectiva co-evolucionista (Guzmán, 2001).

Um dos maiores desafios para os produtores rurais e o poder público é identificar instrumentos que possibilitem a recuperação das APP's sem colocar em risco o meio de ganho financeiro que permite a sobrevivência das pessoas inseridas na microbacia. Sob tais circunstâncias, o emprego do Pagamento por Serviços Ambientais pode ser considerado um sistema promissor a ser implantado. Neste sistema aqueles que se beneficiam dos serviços ambientais são incentivados a pagar por sua manutenção, seguindo seus próprios interesses de melhoria do bem-estar (KAWAICHI e MIRANDA, 2008). O recurso adquirido permite ao produtor melhorar suas técnicas de manutenção do bem comum (a água) (BARBOSA et al., 2009). Segundo Estrada e Quitero (2003) o Pagamento de Serviços Ambientais é considerado um dos mecanismos mais inovadores para se gerar benefícios sociais e ambientais, pois tem impacto tanto no uso da terra quanto no bem-estar dos produtores em situação de vulnerabilidade econômica.

Diante do exposto objetivou-se: (a) identificar quais as principais dificuldades encontradas pelos produtores rurais na tomada de medidas de conservação das APP's; (b) elaborar uma proposta de Pagamento por Serviços Ambientais na microbacia hidrográfica Mariana, na perspectiva de contribuir com subsídios para a criação de alternativas de recuperação das APP's degradadas.

\section{MÉTODOS}

\section{Área de estudo}

A microbacia hidrográfica Mariana (MBM) com área de 5.785 hectares localiza-se no município de Alta Floresta, situado entre as coordenadas de $56^{\circ} 10^{\prime}$ a $5^{\circ} 50^{\prime}$ de longitude $\mathrm{W}$ e de $9^{\circ} 52^{\prime}$ a $9^{\circ} 61^{\prime}$ de latitude S (Figura I). 


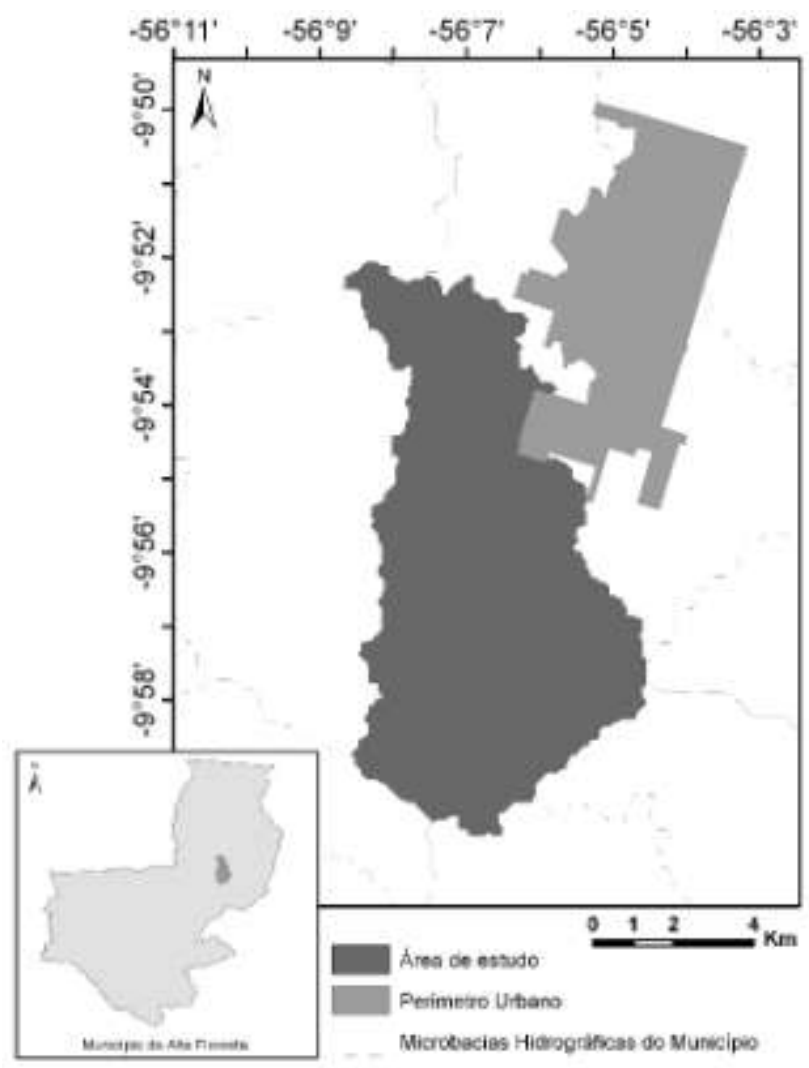

Figura 1 - Microbacia Mariana no contexto municipal e estadual.

Fonte: próprios autores

A população do município de Alta Floresta totaliza 49.164 habitantes, sendo que 42.718 residem na zona urbana e 6.446 na rural (IBGE, 2017). De acordo com o Atlas de Desenvolvimento Humano o Índice de Desenvolvimento Humano (IDH-M) municipal é de 0,714 mostrando-se abaixo do IDH do Estado $(0,725)$ e do Brasil $(0,730)$ (PNUD, 2013). A economia é sustentada por meio da pecuária extensiva e da agricultura.

A vegetação presente na microbacia é constituída basicamente por Floresta Ombrófila, típica em áreas de transição entre a Floresta Amazônica, onde são vistas diversas espécies vegetacionais, como a castanheira, comumente encontrada no bioma Amazônia (BRASIL, 1980; MATO GROSSO, 2002). O relevo é formado pelo Planalto Apiacás-Sucurundi e a Depressão
Interplanáltica Amazônia Meridional (MORENO et al., 2007). Os solos variam de Argissolo amarelo/vermelho-amarelo, Latossolo e solos Hidromórficos, porém este em menor quantidade. Esses tipos de solos são considerados de baixa e média fertilidade, com presença de altos teores de potássio, cálcio, magnésio, matéria orgânica e baixos teores de fósforo (FERREIRA, 2001).

Conforme a classificação Koppen atualizada por Alvares et al. (2013) o clima da região é tropical de monções (Am), com nítida estação seca. Sua média pluviométrica é de 2.213,37 mm (CAIONI et al., 2014), e sua temperatura fica em torno de $25^{\circ} \mathrm{C}$, com máximas e mínimas de $33^{\circ} \mathrm{C}$ e $20,1^{\circ} \mathrm{C}$, respectivamente (TARIFA, 2011).

As bacias hidrográficas que compõem a região são formadas pelos rios Cristalino, Santa 
Helena, Teles Pires e Paranaíta (SOUZA, 2006), sendo em sua maioria recobertas pela Floresta Ombrófila aberta, que se caracterizam por apresentar espécies vegetais de grande porte e elevado espaçamento entre os indivíduos.

A malha hídrica total da qual a MBM faz $\mathrm{km}$ correspondem a riachos de $1^{\mathrm{a}}$ ordem, $15 \mathrm{~km}$ riachos de $2^{\mathrm{a}}$ ordem, $9,5 \mathrm{~km}$ riachos de $3^{\mathrm{a}}$ ordem e 11,5 $\mathrm{km}$ riacho de $4^{\mathrm{a}}$ ordem (Figura II), sendo esta a ordem final até sua foz no Rio Teles Pires, além de 9,8 $\mathrm{km}$ de represas e lagos (CAMARGO, 2009).

parte é representada por 83,39 km. Destes 37,5

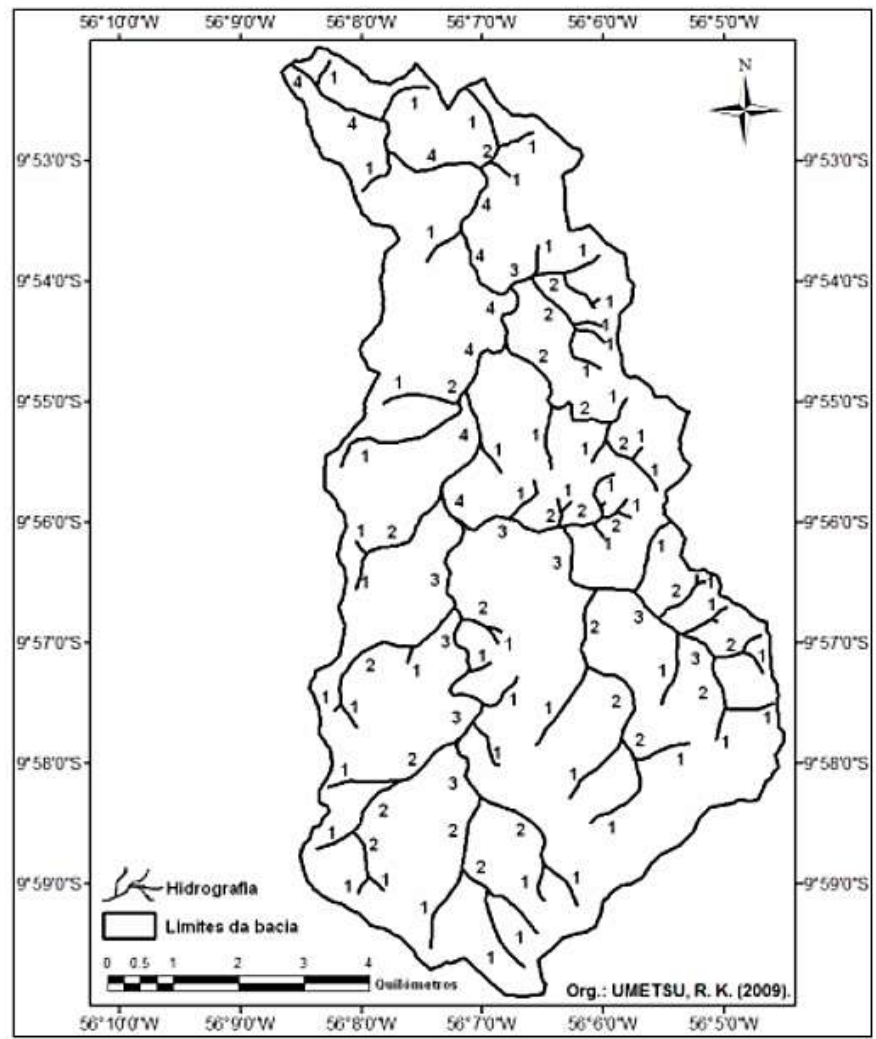

Figura 2 - Árvore hierárquica fluvial da MBM Alta Floresta/MT.

Fonte: Umetsu (2009).

\section{Identificação das dificuldades encontradas pelos produtores rurais}

O presente estudo foi desenvolvido entre 01 de março a 30 de janeiro de 2013, junto aos 95 produtores rurais da MBM. Para atender o primeiro objetivo proposto, realizaram-se três reuniões com os produtores das comunidades Central, Monte Santo, Cristalina, Bom Jesus da
Bela Vista e São Bento. Ao decorrer das reuniões os mesmos expuseram de forma oral e escrita as principais dificuldades evidenciadas durante a prática de recuperação das áreas de APP's degradadas (Figura III). Realizou-se ainda visitas as propriedades a fim de identificar por meio de registro visual e fotográfico os problemas expostos nas reuniões. 


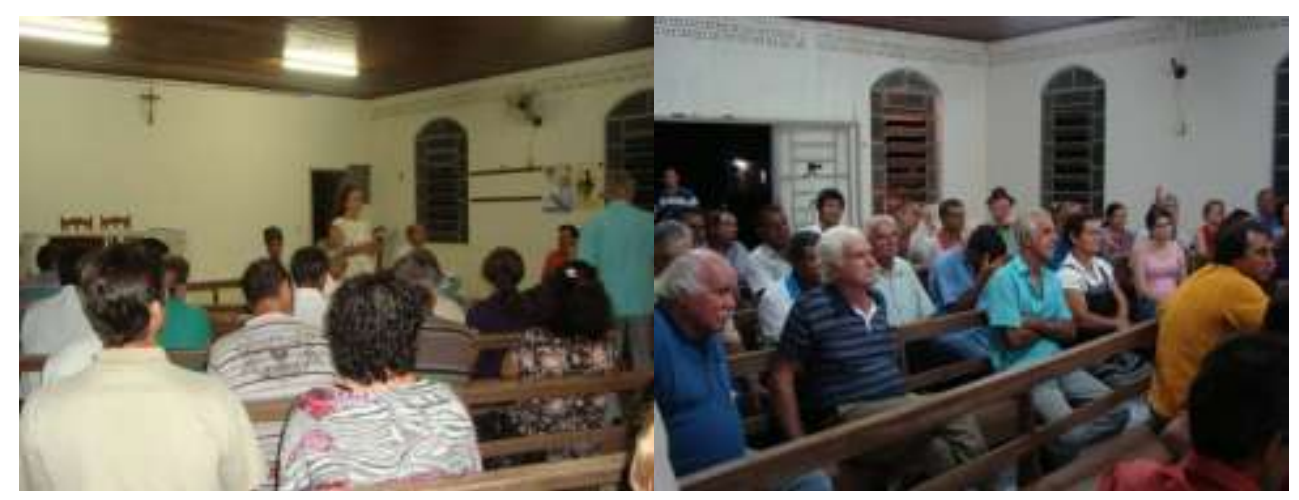

Figura 3 - Reuniões participativas realizadas na MBM, Alta Floresta/MT.

Fonte: próprios autores.

Utilizou-se também dados secundários coletados no projeto Hidroflora desenvolvido pela Secretaria de Meio Ambiente do município de Alta Floresta (SECMA). O questionário aplicado aos produtores rurais continha perguntas (estruturadas e semiestruturadas) referentes à água e a flora de cada propriedade.

A adoção de ambos os métodos é muito importante, visto que questionários não estruturados envolvem perguntas abertas o que possibilita ao entrevistado expressar suas opiniões com suas próprias palavras (CHRISTOFOLETTI, 1999) e questionários estruturados permitem a obtenção de respostas mais direcionadas ao objetivo almejado no estudo.

A partir dos dados obtidos os mesmos foram tabulados e neles realizados a estatística descritiva (média, mínimo e máximo) no programa $\mathrm{R}$ versão 2.1 .13 , em seguida foram geradas tabelas e representações gráficas que possibilitaram tecer as análises e discussões.

\section{Desenvolvimento da proposta de pagamento ambiental}

Com o intuito de atender o segundo objetivo proposto, primeiramente foi realizado um levantamento teórico a respeito de instrumentos de políticas públicas ambientais já implantadas no município de Alta Floresta. Segundo Malhotra (2001), este tipo de coleta de informações é fundamental, visto que permite uma melhor compreensão do contexto local.

Em seguida foi realizado um levantamento das características da microbacia, a citar: principais usos da terra nas áreas adjacentes as APP's, número de nascentes, número de APP's preservadas e degradas e total de unidades consumidoras de água no perímetro urbano (Figuras IV e V). Os dados obtidos foram disponibilizados pelo Projeto Hidroflora, Instituto Centro de Vida (ICV) e Companhia de água do Brasil (CAB). 


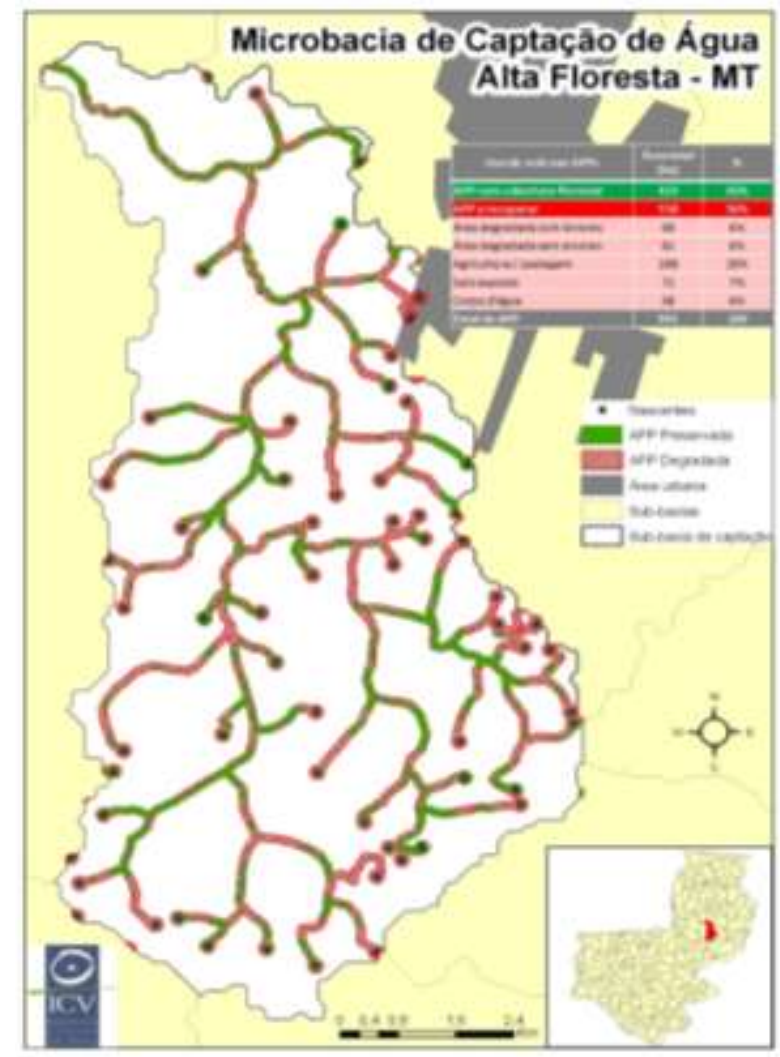

Figura 4 - Localização da Microbacia de Capitação de água de Alta Floresta/MT.

Fonte: ICV.

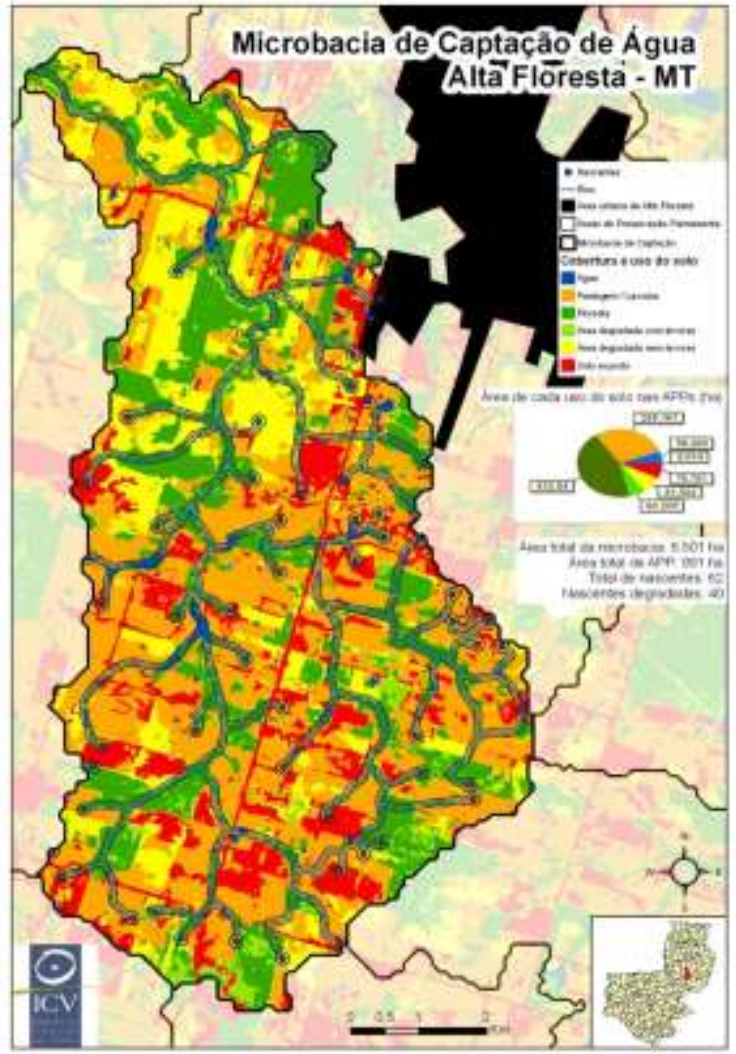

Figura 5: Uso e ocupação da MBM, Município de Alta Floresta/MT.

Fonte: ICV. 
A partir dos dados analisados foi possível elaborar uma proposta de Pagamentos

\section{RESULTADOS E DISCUSSÃO}

\section{Perspectiva dos produtores rurais na recupe- ração das APP's}

Conforme relatos dos produtores rurais são diversos os obstáculos encontrados durante a tomada de medidas de recuperação das APP's, indo desde a falta de recurso financeiro e técnico ao descontentamento com o poder público.

De acordo com os dados do projeto Hidroflora $52,11 \%$ das propriedades rurais possuem pouca ou nenhuma mata ciliar em suas nascentes. Esse cenário é preocupante, visto que $76 \%$ dos entrevistados já afirmam terem observado reduções na disponibilidade hídrica das nascentes. Para diversos autores (SILVÉRIO et al., 2015; CAIONI et al., 2017) este resultado é esperado, vista que a perda das matas ciliares leva ao aumento excessivo da temperatura superficial que por sua vez contribui para o aumento da evaporação. OLIVEIRA et al., (2013) mencionam ainda que as matas ciliares funcionam como uma espécie de esponja, evitando a entrada de enxurradas e regulando o ciclo da água.

A renda mensal entre os produtores variou de 800 a 8 mil reais. Essa discrepância esteve intimamente relacionada ao tamanho de cada propriedade, uma vez que estas variaram de 2 a 290,4 hectares. Em relação à faixa etária a maior parte dos agricultores apresentaram idades entre 55 e 59 anos fato este que dificulta a realização de determinadas atividades, uma vez que algumas necessitam de elevados esforços físicos. por Serviços ambientais (PSA) que melhor atendesse as necessidades dos produtores rurais.

A presença de animais em APP's também demonstrou dificultar a recuperação de algumas áreas, para os produtores rurais os animais compreendem tanto a fauna doméstica (Galinhas e Porcos) quanto silvestre (Maritacas e Antas), sendo que a espécie que mais tem apresentado danos aos reflorestamentos ( $83 \%$ dos casos) é a capivara, esta que segundo os moradores andam geralmente em grupos de aproximados 20 indivíduos. No que se refere a "perspectiva futura dos produtores em relação à propriedade" $11,30 \%$ pensam em abandonar a propriedade e irem para a cidade, corroborando com o êxodo rural.

Durante as reuniões foi possível observar ainda um crescente descontentamento dos agricultores com relação ao poder público estadual e federal. Segundo os agricultores os mesmos têm consciência da importância da recuperação das APP's degradas, contudo faltam-lhes recursos financeiros para a tomada dessas medidas, visto que a grande maioria vive da agricultura familiar e da pecuária leiteira.

Embora haja a necessidade imediata de implantação de políticas públicas voltadas para o auxílio dos produtores, é preciso salientar que as mesmas devem ser solidas e condizentes com a realidade local, pois já há uma desconfiança local nos programas governamentais, mediante a existência histórica de insucesso de antigos programas.

Por meio de visitas a campo, pode-se evidenciar a necessidade da construção de curvas 
de nível nas áreas adjacentes as APP's, a fim de amenizar o processo de erosão que tem se intensificado em algumas áreas, estas decorrentes da compactação do solo por pisoteio do gado nas áreas de pastagem. De acordo com Camargo e Alleoni (1997) a compactação do solo, além de prejudicar a percolação da água, afeta ainda o crescimento radicular e os processos de aeração e condutividade térmica.

De modo geral constatou-se a necessidade de intervenção do poder público como agente mediador e fornecedor de meios alternativos para a recuperação das áreas degradadas.

\section{Proposta de pagamento por serviços ambientais}

Quanto ao nível de conhecimento e interesse de implantação do PSA, verificou-se que $51,85 \%$ dos produtores rurais desconhecem o assunto e somente $48,15 \%$ sabem de que se trata. Quando questionados se era de interesse a aplicação desse programa, 90,69\% dos produtores demonstraram ser a favor e 9,31\% não, ficando evidente o elevado interesse na implantação do programa. Segundo May e
Geluda (2005) estes resultados revelam-se positivos do ponto de vista de implantação do PSA, visto que para o alcance do seu sucesso é crucial que a participação dos proprietários seja voluntária.

Pelos resultados encontrados sugere-se um projeto de Pagamento de Serviços Ambientais na MBM, fundamentado na parceria entre a prefeitura municipal de Alta Floresta e a empresa privada Companhia de Águas do Brasil (CAB), onde essa cobrará uma taxa $\mathrm{R} \$ 0,85$ (oitenta e cinco centavos) na conta de água dos consumidores, possibilitando a criação de um fundo financeiro que teria como intuito recuperar e preservar as APP's da microbacia.

De acordo com dados de 2012 cedidos pela $\mathrm{CAB}$, essa mesma empresa fornece água encanada para 11.695 casas no perímetro urbano do município de Alta floresta. Desta forma se for cobrada uma taxa de $\mathrm{R} \$ 0,85$ centavos por domicilio, é possível estimar uma margem de renda mensal total bruta de $\mathrm{R} \$ 9.940,75$ o que resultaria em aproximadamente $\mathrm{R} \$ 104,39$ para cada propriedade situada na microbacia (Tabela I).

Tabela 1 - Cálculo de arrecadação liquida por propriedade

\begin{tabular}{cc}
\hline Descrição & Valores \\
\hline Taxa de contribuição & $\mathrm{R} \$ 0,85$ \\
Número de propriedades rurais que compõem a MBM & 95 \\
Número de residências urbanas consumidoras de água & 11.695 \\
Arrecadação Bruta Total & $0,85 * 11.695=\mathrm{R} \$ 9.940,75$ \\
Arrecadação liquida por Propriedade & $9.940,75 / 95=\mathrm{R} \$ 104,39$ \\
\hline
\end{tabular}

Fonte: próprios autores

Outro ponto importante é que a taxa estipulada seja atualizada anualmente para que o valor repassado aos agricultores não fique defasado. Ressalta-se ainda a importância de 
discutir com os agricultores sobre um destino seguro para esse recurso financeiro, visto que o mesmo deve ser usado de forma igualitária por todos os membros da comunidade. Uma proposta é a criação de um viveiro florestal com o intuito de produzir mudas de espécies nativas, com o acompanhamento de um técnico florestal responsável pela entrega das mudas em condições ideais para o plantio.

Outra sugestão é a criação de uma conta para cada proprietário, onde esses recebam mensalmente uma parte do capital arrecadado. O recurso será empregado na compra de equipamentos utilizados nas propriedades visando à recuperação da área como, por exemplo, lascas de madeira, arame, cavadeira e entre outros.

\section{CONCLUSÃO}

As Áreas de Preservação Permanente que constituem a unidade hidrográfica estudada apresentam-se em avançado estado de degradação, fazendo-se necessário a tomada de medidas de recuperação imediata.

Pode-se constatar que os produtores da MBM compreendem a importância da recuperação das Áreas de Preservação Permanente, e até possuem a intenção de recuperar essas áreas, contudo a falta de recursos financeiros tem se mostrado o principal obstáculo para a tomada de medidas necessárias. A adoção do programa de Pagamentos por Serviços Ambientais (PSA) constitui-se em um mecanismo viável de solução dos problemas relacionados à degradação das Áreas de
Preservação Permanente da MBM, uma vez que é de grande interesse dos produtores a criação de um PSA no local, e que esta possui um gigantesco potencial hídrico. Contudo é necessário ressaltar que para o sucesso da implantação do modelo de PSA proposto, devese haver a integração entre o poder público e as pessoas envolvidas, visto que a água é um bem comum.

\section{REFERÊNCIAS}

ALTIERI, M. A. Agroecologia: as bases cientificas da agricultura alternativa. 2. ed. Rio de Janeiro: PTA / FASE; 1989.

ALVARES, C. A.; STAPE, J. L.; SENTELHAS, P. C.; GONÇALVES, J. L. de M.; SPAROVEK, G. Köppen's climate classification map for Brazil. Meteorologische Zeitschrift. Eletr. Enf. [Internet], 2013 [acesso em 10 janeiro 2018]; 22: 711-728. Disponível em: < http://docserver.ingentaconnect.com/deliver/connect/s chweiz/09412948/v22n6/s8.pdf?expires $=1515599324$ $\&$ id $=0000 \&$ titleid $=1292 \&$ checksum $=E 51 D 593 D 9 D 35$ 4C498C3B762652E30CA2>.

BARBOSA, J. M.; ABRAHÃO, R. Q.; CANADA, C. B. S.; MARIOTONI, C. A. Pagamento por serviços ambientais em área de proteção aos mananciais: uma proposta para a região do ribeirão Balainho, Suzano, São Paulo. In: SEMINÁRIO DE RECURSOS HÍDRICOS DA BACIA HIDROGRÁFICA DO PARAÍBA DO SUL: RECUPERAÇÃO DE ÁREAS DEGRADADAS, SERVIÇOS AMBIENTAIS E SUSTENTABILIDADE, 2., 2009, Taubaté. Anais... Taubaté: IPABHi, 2009; 357-364.

BECKER, B. K. Revisão das Políticas de Ocupação da Amazônia: é possível identificar modelos para projetar cenários? Parcerias Estratégicas. Eletr. Enf. [Internet], 2001 [acesso em 10 janeiro 2018]; 12: 135-159. Disponível em: < http://seer.cgee.org.br/index.php/parcerias_estrategica s/article/viewFile/178/172>.

BRASIL. Radam Brasil. Programa de Integração Nacional. Folha SC. 21 Juruena: geologia, geomorfologia, pedologia, vegetação e uso potencial da terra. Rio de Janeiro: Ministério das Minas e Energia/Departamento Nacional da Produção Mineral. 1980 . 
CAIONI, C.; CAIONI, S.; SILVA, A. C. S.; PARENTE, T.L.; ARAUJO, O.S. Análise da distribuição pluviométrica e de ocorrência do fenômeno climático ENOS no município de Alta Floresta/MT. Enciclopédia Biosfera. Eletr. Enf. [Internet], 2014 [acesso em 7 janeiro 2018]; 109 190: 2656-2666. Disponível em: < http://www.conhecer.org.br/enciclop/2014b/MULTID ISCIPLINAR/Analise\%20da\%20distribuicao.pdf > .

CAIONI, C.; NEVES, S. M. A. S; CAIONI, S; BONINI, I; PARENTE, T. L; SILVA, A. C. S. Dinâmica da temperatura superficial da microbacia Pedra do Índio durante a seca de 2013. Revista Espacios. Eletr. Enf. [Internet], 2017 [acesso em 10 janeiro 2018]; 38(38): 09-20. Disponivel em : < http://www.revistaespacios.com/a17v38n38/a17v38n3 8p09.pdf $>$.

\section{CAMARGO, M. F. Sub-bacia Mariana:}

caracterização físico-química do solo da área ciliar e levantamento do uso e ocupação para fins de conservação ambiental [Dissertação de Mestrado]. Mato Grosso: Universidade do Estado de Mato Grosso, 2009, [acesso em 10 maio 2018]. Disponível em:<http://www.unemat.br/prppg/ppgca/teses/2010/01 $0 . p d f>$

CAMARGO, O. A.; ALLEONI, L. R. F. Compactação do solo e o desenvolvimento das plantas; 1997.

CHRISTOFOLETTI, A. Modelagem de sistemas ambientais. São Paulo: Edgard Blücher; 1999.

DUBREUIL, V.; DEBORTOLI, N.; LINDOSO, D.; DURIEUX, L.; NÉDÉLEC, V.; ARVOR, D.; BURSZTYN, M. Percepções ao longo da BR 163 e no Noroeste do Mato Grosso: Sorriso, Alta Floresta. 2009.

ESTRADA, R. D.; QUITERO, M. Propuesta metodológica para el analise de cuenca : uma alternativa para corregir las deficiências detectadas en la implementicion del pago por sevicios ambientales. In: CONGRESSO LATINOAMERICANO DE MANEJO DE CUENCAS HIDROGRÁFICAS, FORO REGIONAL SOBRE SISTEMAS DE PAGO POR SERVICIOS AMBIENTALES, 3., 2003, Arequipa. Anais... Arequipa, 2003. p. 1-11.

FERREIRA, J. C. V. Mato Grosso e Seus Municípios. Cuiabá: Secretaria de Estado de Educação; 2001.

GUZMÁN, E. S. Bases sociológicas de la agroecología. In: Encontro Internacional sobre agroecologia e desenvolvimento rural sustentável, 2001, Botucatu. Anais... Botucatu: FCA/UNESP, 2001.
IBGE. Instituto Brasileiro de Geografia e Estatística. Cidades. Disponível em: <

https://ww2.ibge.gov.br/cidadesat/painel/painel.php?c odmun=510025 > . Acesso em: 03 Set. 2017.

KAWAICHI, V. M.; MIRANDA, S. H. H. G. O desempenho da Costa Rica na adoção do Pagamento por Serviços Ambientais (PSA) como política pública ambiental. In: SIMPÓSIO INTERNACIONAL DE INICIAÇÃO CIENTÍFICA DA USP, 16, 2008, Piracicaba. Anais... Piracicaba: UPS, 2008. p. 1-22.

LACORTE, I. M.; ALMEIDA, M. R. R. Impactos ambientais em Áreas de Preservação Permanente de centros urbanos: o caso da bacia do Córrego Liso em Uberlândia. Enciclopédia Biosfera, Eletr. Enf. [Internet], 2015 [acesso em 10 janeiro 2018]; 11(22) 1464-1475. Disponível em : < http://www.conhecer.org.br/enciclop/2015c/agrarias/i mpactos\%20ambientais.pdf>

MAlHotra, N. Pesquisa de Marketing: uma orientação aplicada. 3. ed. Porto Alegre: Bookman; 2001.

MATO GROSSO. Mapa de Vegetação. Zoneamento Sócio-Econômico Ecológico. 2002. Ministério de Integração Nacional - PRODEAGRO. Disponível em: <http://www.seplan.mt.gov.br/>. Acesso em: 20 abr. 2013.

MAY, P. H.; GELUDA, L. Pagamentos por serviços ecossistêmicos para manutenção de práticas agrícolas sustentáveis em microbacias do norte e noroeste do Rio de Janeiro. In: ENCONTRO DA SOCIEDADE BRASILEIRA DE ECONOMIA ECOLÓGICA: O MEIO AMBIENTE NAS POLÍTICAS PÚBLICAS, 6, 2005, Brasilia. Anais... Brasilia, 2005. p. 1-25.

OLIVEIRA, E. M. D.; SANTOS, W. M. B.; MORAIS, J. L. D.; BASSETTI, F. D. J.; BERGAMASCO, R. Percepção ambiental e sensibilização de alunos de colégio estadual sobre a preservação de nascente. Revista Eletrônica do Mestrado em Educação Ambiental, Eletr. Enf. [Internet], 2013 [acesso em 3 janeiro 2018]; 30(1): 2337. Disponível em: < https://www.seer.furg.br/remea/article/view/3532/221 6>.

PNUD - PROGRAMA DAS NAÇÕES UNIDAS PARA O DESENVOLVIMENTO. Atlas de Desenvolvimento Humano - Índice de Desenvolvimento Humano (IDH) dos municípios brasileiros. 2013. Disponível em:

<http://www.br.undp.org/content/brazil/pt/home/>. Acessado em: 26 Ago. 2013.

SANTOS, G. V.; DIAS, H. C. T.; SILVA, A. P. S.; MACEDO, M. N. C. Análise hidrológica e socioambiental da bacia hidrográfica do córrego 
Romão dos Reis, Viçosa-MG. Revista Árvore, Eletr. Enf. [Internet], 2007 [acesso em 8 janeiro 2018];

31(5):931-940. Disponível em: <

http://www.scielo.br/pdf/rarv/v31n5/a17v31n5.pdf>.

SILVA, R.R.; WERTH, D.; AVISSAR, R. The future of Amazon Basin hydrometeorology. J. Clim. 2017.

SILVÉRIO, D. V.; BRANDO, P. M.; MACEDO, M. N.; BECK, P. S.; BUSTAMANTE, M.; COE, M. T. Agricultural expansion dominates climate changes in southeastern Amazonia: The overlooked non-GHG forcing. Environmental Research Letters, Eletr. Enf. [Internet], 2015 [acesso em 8 janeiro 2018]; 10(10): 104015. Disponivel em: < http://iopscience.iop.org/article/10.1088/17489326/10/10/104015/pdf >.

\section{SOUZA, S. C. Desmatamento e Clima em Alta}

Floresta - Amazônia Mato-grossense [Dissertação de Mestrado]. Mato Grosso: Universidade Federal de Mato Grosso, 2006 [acesso em 10 janeiro 2018].

Disponível em: <

http://www.geografiaufmt.com.br/index.php/biblioteca -dissertacoes/send/30-dissertacoes/39-desmatamentoe-clima-em-alta-floresta-amazonia-mato-grossense>.

TARIFA, J. R. Mato Grosso: clima - análise e representação cartográfica. Cuiabá: Entrelinhas; 2011.

UMETSU, R. K. Estudo eco-hidrológico da bacia hidrográfica Mariana, afluente do Rio Taxidermista, Alta Floresta - MT [Tese de doutorado]. São Carlos: Universidade Federal de São Carlos, 2009 [acesso em 10 janeiro 2018]. Disponível em: < https://repositorio.ufscar.br/bitstream/handle/ufscar/16 80/3113.pdf? sequence $=1$ \&isAllowed $=\mathrm{y}>$.

ZOBY, J. L. G.; OLIVEIRA, F. R. Panorama da qualidade das águas subterrâneas no Brasil. Brasília: Agência Nacional de Águas (ANA). Brasilia: BINAGRI; 2005.

\section{Charles Caioni}

Doutorando em ecologia e conservação pela Universidade do Estado de Mato Grosso. Atua nas áreas de Mudanças Climáticas, Climatologia Florestal, Meteorologia Florestal e Sensoriamento Remoto.

\section{Edgley Pereira Silva}

Professor adjunto ao departamento de agronomia da Universidade do Estado de Mato Grosso. Realiza estudos nas linhas de pesquisa: Ciência do solo, Geoprocessamento, Climatologia e Leitura de ambiente.

\section{Delmonte Roboredo}

Professor adjunto ao departamento de agronomia da
Universidade do Estado de Mato Grosso. Atua nas áreas de desenvolvimento rural sustentável, agricultura familiar, políticas públicas e organização social.

\section{Gessica de Jesus Oliveira Silva}

Graduanda em Geografia pela Universidade do Estado de Mato Grosso. Atua nas áreas de Geotecnologias, Sensoriamento Remoto, Meio Ambiente e Ensino de Geografia, Culturas, Políticas Públicas e índices de queimada.

Sheila Caioni
Doutoranda em Agronomia pela Universidade
Estadual Paulista. Atua na área de fitotecnia, com
ênfase em adubação e nutrição de plantas e
micronutrientes, nas culturas de soja e milho.

